\title{
Average Concentration Normalized by \\ Weight
}

National Cancer Institute

\section{Source}

National Cancer Institute. Average Concentration Normalized by Weight. NCI Thesaurus.

Code C92370.

AUCT AU divided by TAU and then divided by the weight. 